\title{
Iron oxidation state of mantle minerals determined from $L$ emission spectra by the electron microprobe
}

\author{
Heidi E. Höfer, Gerhard P. Brey and Alan B. Woodland \\ University of Frankfurt, Germany.
}

\section{INTRODUCTION}

The determination of the oxidation state of transition metals by electron probe microanalysis (EPMA) is of long-standing interest for geological and technical problems. In the last years, several alternative methods to determine iron speciation on the micrometer scale have been developed. Amongst these are XANES and XAFS with synchrotron radiation (see Wilke et al. 2001 and references) and $\mathrm{X}$-ray photoelectron spectroscopy (XPS, e. g., Raeburn et al. 1997). These methods have a relatively poor spatial resolution of several tens to hundreds of $\mu \mathrm{m}$, only slightly better than the recently developed Mössbauer milliprobe (McCammon 1994). A further method is EELS, using a transmission electron microscope (e. g., van Aken et al. 2002) which has a resolution of $1 \mu \mathrm{m}$ for $\mathrm{Fe}^{2+} / \mathrm{Fe}^{3+}$ determination. In geoscience, these methods are all useful, but limitations exist such as the ready availability of a synchrotron, the amount of sample material needed, the destructive preparation for EELS. The $\mathrm{Fe}^{2+} / \mathrm{Fe}^{3+}$ determination by electron microprobe bears several advantages: (i) the small sample amount needed, (ii) the small sampling volume $\leq 1 \mu \mathrm{m}^{3}$, (iii) the simultaneous in situ $\mathrm{Fe}^{2+} / \mathrm{Fe}^{3+}$ determination and quantitative chemical analysis even at very low iron contents, (iv) the easy routine sample preparation, (v) the ready availability of an electron microprobe in comparison to a synchrotron or TEM.

There have been several attempts in the past to determine the iron oxidation state by electron microprobe. Yet, only semiquantitative $\mathrm{Fe}^{2+} / \mathrm{Fe}^{3+}$ estimations were achieved so far (e. g., Pavicevic et al. 1989, Armstrong 1999, Fialin 2001). We developed a new method (Höfer et al. 1994) that allows accurate measurement of the critical Xray intensities that are related to the iron oxidation state in solid samples. This method has been applied successfully for sodic amphiboles by Enders et al. (2000) and for wüstites by our group (Höfer et al. 2000). Our latest results with synthetic garnets (Höfer and Brey, in prep.) show that the raw microprobe data can be empirically corrected for self-absorption and that an unambiguous and accurate determination of $\mathrm{Fe}^{2+} / \mathrm{Fe}^{3+}$ is possible by electron microprobe.

\section{RESULTS AND DISCUSSION}

We have established a method (,flank method“; Höfer et al. 1994, 2000) to determine the iron oxidation state of minerals by electron microprobe. An additional improvement is the simoultaneous quantitative analysis of the chemical composition at the same spot. The flank method is based on the iron L emission spectra which are not only sensitive to $\mathrm{Fe}^{2+} / \mathrm{Fe}^{3+}$, but are also affected by the electronic environment of the iron atoms, i.e. the coordination polyhedra and the crystal structure. We first investigated well-defined synthetic garnet samples covering a large bulk compositional and $\mathrm{Fe}^{2+} / \mathrm{Fe}^{3+}$ range. Fig. 1 shows the energy shift and the change in intensity ratios of the FeL $\alpha$ and FeL $\beta$ X-ray emission spectra of almandine and andradite.

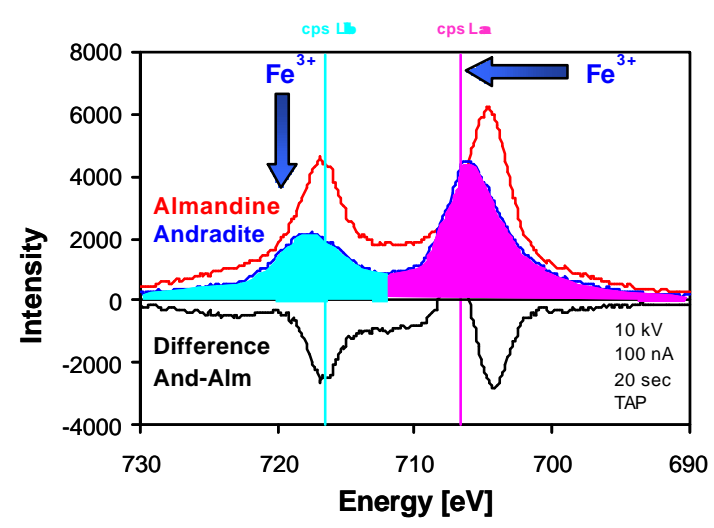

Figure 1: $F e L \alpha$ and $F e L \beta$ X-ray emission spectra of almandine $\mathrm{Fe}_{3}{ }^{2+} \mathrm{Al}_{2}{ }^{3+} \mathrm{Si}_{3} \mathrm{O}_{12}$ and andradite $\mathrm{Ca}_{3}{ }^{2+} \mathrm{Fe}_{2}{ }^{3+} \mathrm{Si}_{3} \mathrm{O}_{12}$. The maxima are shifted to higher energies for the ferric iron containing garnet with a concomitant decrease of the $\mathrm{B} / \mathrm{L} \alpha$ intensity ratio. The positions for the flank method measurements are marked by the vertical lines and are situated in the minimum and maximum of the difference spectrum.

For flank method measurements, 27700 counts (for a $1 \mathrm{~s}$ precision $=0.6 \%$ ) are accumulated at the positions marked by the vertical lines in Fig. 1 as described in Höfer et al. (1994) and (2000). The statistical error on 
the FeL $\alpha$ and FeL $\beta$ intensity is therefore identical for samples with low or high Fe content. We established the method using an accelerating voltage of $10 \mathrm{kV}$ assuming that under these conditions, disturbing absorption effects would be minimal. As will be shown in Höfer and Brey (in prep.), self-absorption is in fact the main cause for the $\mathrm{Fe}^{2+} / \mathrm{Fe}^{3+}$-dependence of the FeL emission spectra in Fig. 1 and should be maximized by increasing the accelerating voltage to $15 \mathrm{kV}$. The first set of data on synthetic garnets (Figs. 1, 2) was achieved at $10 \mathrm{kV}$ using a Cameca SX50 electron microprobe, the second set of data on natural mantle minerals (Figs. 3-6) were taken at $15 \mathrm{kV}$ with a Jeol Superprobe JXA-8900 electron microprobe.

\section{SYNTHETIC GARNETS}

Fig. 2 shows the flank method results of all the synthetic garnet samples used in our work (Höfer and Brey, in prep.). The ratios $L \beta / L \alpha$ are plotted versus the total iron content irrespective of their $\mathrm{Fe}^{3+}$ content. The diagram shows systematic variations of the ratio cps $L \beta /$ cps $L \alpha$ with total iron content if crystallographic aspects concerning the cation exchange mechanism is taken into account: The pyrope-almandine garnets plot along the regression line I. All other samples containing only $\mathrm{Fe}^{2+}$ and $\mathrm{Mg}, \mathrm{Mn}, \mathrm{Ca}$, or even $\mathrm{Cr}$ replacing $\mathrm{Al}$, also plot on this line, regardless of their composition. In these garnets, $\mathrm{Fe}^{2+}$ is exchanged by divalent cations on the dodecahedral site (here designated as "group I garnets"). In the almandine-"skiagite" solid solution, $\mathrm{Fe}^{3+}$ replaces $\mathrm{Al}^{3+}$ on the octahedral site. In pure "skiagite", the octahedral site is filled only with $\mathrm{Fe}^{3+}$ and the dodecahedral site with $\mathrm{Fe}^{2+}$. The ferric to total iron ratio is 0.4 . This ratio increases in "skiagite"andradite garnets and reaches 1 in andradite. However, structurally the $\mathrm{Fe}^{3+}$ content remains constant per formula unit since the octahedral site is filled by $\mathrm{Fe}^{3+}$ in andradite-"skiagites". The total iron content is changed due to the replacement of $\mathrm{Fe}^{2+}$ by $\mathrm{Ca}^{2+}$, a similar process as in the group I garnets. In the andraditegrossular garnets, $\mathrm{Fe}^{3+}$ exchanges with $\mathrm{Al}^{3+}$ on the octahedral site. A comparison of these results with Mössbauer data shows that the electron microprobe reveals details concerning the crystallographic and electronic environment of the crystallographic site previously unknown (Höfer 2002).

From the systematic behaviour of the regression lines in Fig. 2 it is now possible to correct for the selfabsorption effect of $\mathrm{Fe}^{2+}$ and $\mathrm{Fe}^{3+}$ separately (Höfer and Brey, in prep.) and to determine $\mathrm{Fe}^{3+} / \Sigma \mathrm{Fe}$ unambiguously. Another important result is that the data are only dependent on the $\mathrm{Fe}^{2+} / \mathrm{Fe}^{3+}$ content and are not affected by the chemical composition of the garnets.

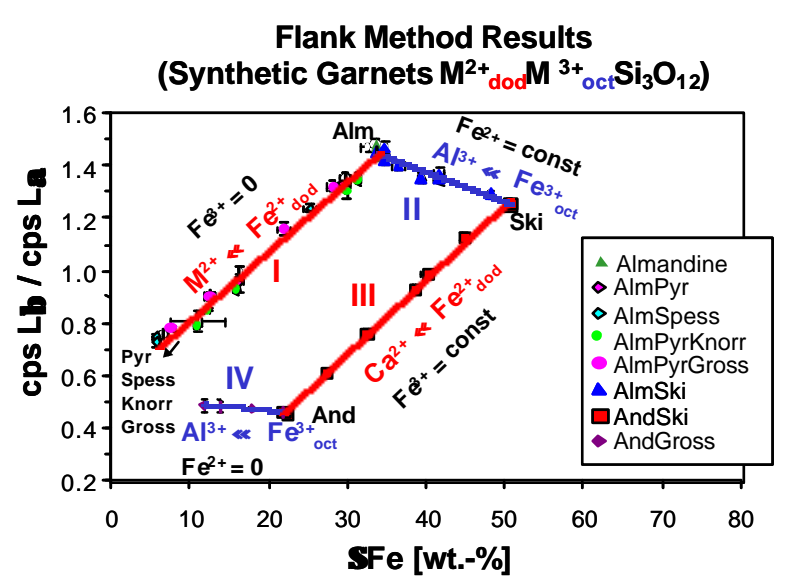

Figure 2: Flank method ratio $L / L \alpha \alpha$ versus total iron content showing systematic variations with cation exchange on dodecahedral and octahedral crystallographic sites for synthetic garnets $(10 \mathrm{kV}, 60 \mathrm{nA})$.

\section{MANTLE MINERALS}

The knowledge of $\mathrm{Fe}^{2+} / \mathrm{Fe}^{3+}$ in mantle minerals such as garnets or clinopyroxenes is important for the $\mathrm{fO}_{2}$ determination within the mantle (Woodland and Peltonen 1998) or as an indicator for mantle metasomatism. We extended our studies to natural garnet and pyroxene megacrysts and garnet and clinopyroxene separates from xenoliths from various localities of the Kapvaal craton and from the Biu and Jos Plateaus in Nigeria (Rankenburg 2002) for which $\mathrm{Fe}^{3+} / \Sigma \mathrm{Fe}$ was previously determined by Mössbauer spectroscopy. Plotting our first results versus $\mathrm{Fe}^{2+}$ determined from Mössbauer spectroscopy (Fig. 3) yields a linear relationship both for garnets and for pyroxenes. The different slopes of the correlation lines are not surprising since the FeL emission lines used for these determinations are affected by the crystallographic environment.

After applying our new correction procedure for selfabsorption (Höfer and Brey, in prep.), a value " $\Delta$ ratio cps L $\beta /$ cps L $\alpha$ " plotted versus $\mathrm{Fe}^{3+}$ as known from Mössbauer spectrosopy also yields a linear relationship (Fig. 4). As expected, the mantle minerals plot in a cluster at very low $\mathrm{Fe}^{3+}$ concentrations. The "skiagite" and aegirine measurements have been included to show 
the linear relationship that has been proven for synthetic garnets (Höfer and Brey, in prep.). Note that the aegirine is a natural inhomogeneous sample that has only been included as an example for high $\mathrm{Fe}^{3+}$ concentration. The spread of the data is caused by the fact that total iron scatters and was taken as $\mathrm{Fe}^{3+}$.

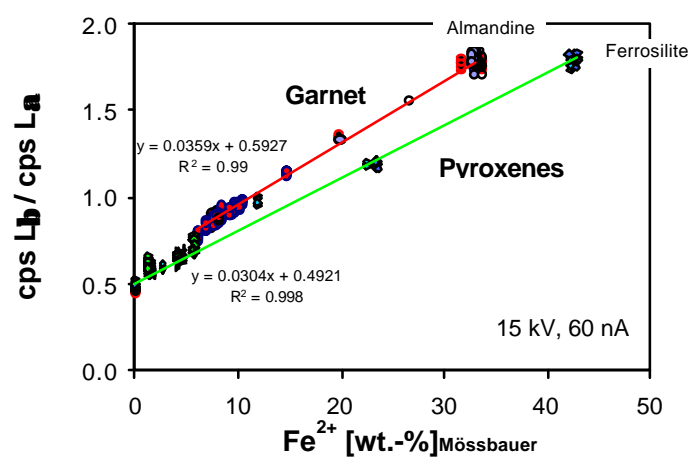

Figure 3: The ratio $L \beta / L \alpha$ obtained from EPMA flank method measurements versus ferrous iron from Mössbauer spectroscopy. Mantle minerals plot in the lower left. Few other natural or synthetic minerals were also included to show the linear relationship.

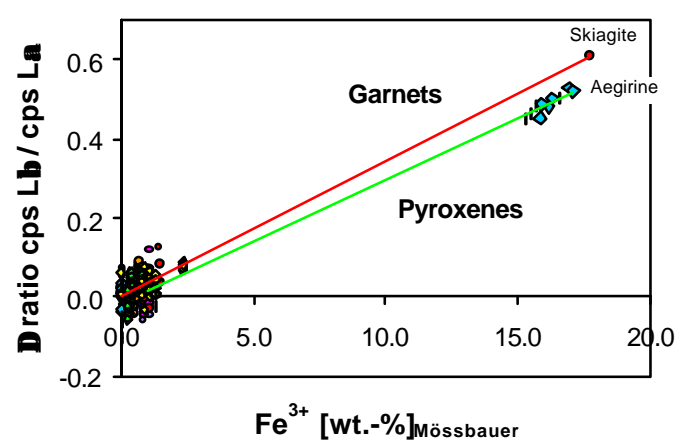

Figure 4: Relationship between the flank method ratio corrected for self-absorption and $\mathrm{Fe}^{3+}$. At this scale, the mantle minerals plot in an unresolved cluster.

Although the data in Fig. 4 seem to plot in a cluster at low iron concentrations, they linearly correlate for garnets (Fig. 5) as well as for pyroxenes (Fig. 6).

The slope of the correlation line for garnets in Fig. 5 is strongly influenced by the $\mathrm{Fe}^{3+}$-rich "skiagite" sample not shown in the diagram. The scatter of two natural and synthetic almandine samples is most probably due to sample inhomogeneities. Besides the Kakanui pyrope standard for electron microprobe (USNM 143968), garnets from megacrysts were analysed. The total iron concentrations range between 7-10 wt.-\% (Nigeria; 1 sample: 15.4 wt. $-\%)$.

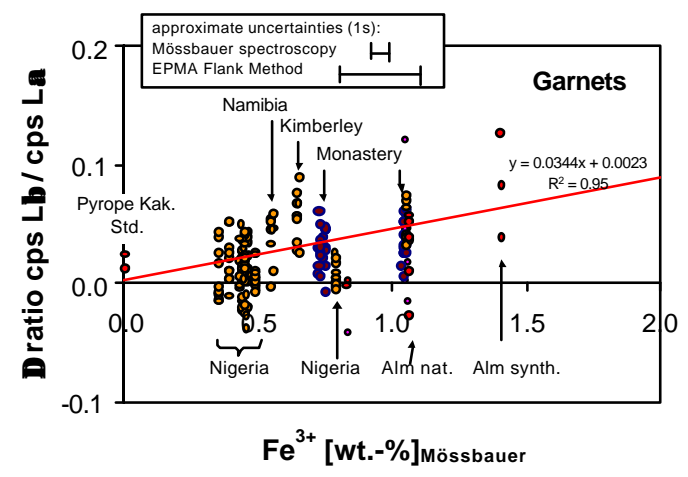

Figure 5 Garnet data from Fig. 4 at higher magnification showing the correlation between the flank method ratio corrected for self-absorption and $\mathrm{Fe}^{3+}$. Note that sample inhomogeneities invisible for Mössbauer spectroscopy as a bulk method are readily reflected in electron microprobe data. Also, the error of Mössbauer spectroscopy is dependent on total iron, while the flank method error is independent and constant.

The iron contents for the analysed pyroxenes (Fig. 6) range between 1.49 and $1.69 \pm 0.01$ wt. $\% \mathrm{Fe}$ (Kimberley cpx), and are $4.65 \pm 0.02$ and $6.04 \pm 0.03$ wt. $\%$ Fe for Monastery cpx and opx, respectively. Further samples are electron microprobe standards (Kakanui augite: USNM 122142; Roberts Victor omphacite: USNM 110607). The regression lines were established in two different ways:

(i) by calculating a linear regression with all data points. This yields an offset that is not yet understood and may be due to a systematic error in Mössbauer $\mathrm{Fe}^{3+}$ determination;

(ii) by fixing the zero point and neglecting the 2 Kimberley samples with lowest $\mathrm{Fe}^{3+}$ (and also lowest total $\mathrm{Fe}$ ) since these should have the largest Mössbauer error. This line corresponds better to the samples with a higher $\mathrm{Fe}^{3+}$ content and should be taken as the correct fit.

Since these samples contain less total Fe than the above garnets, the Mössbauer error grows in comparison to the electron microprobe flank method error. 


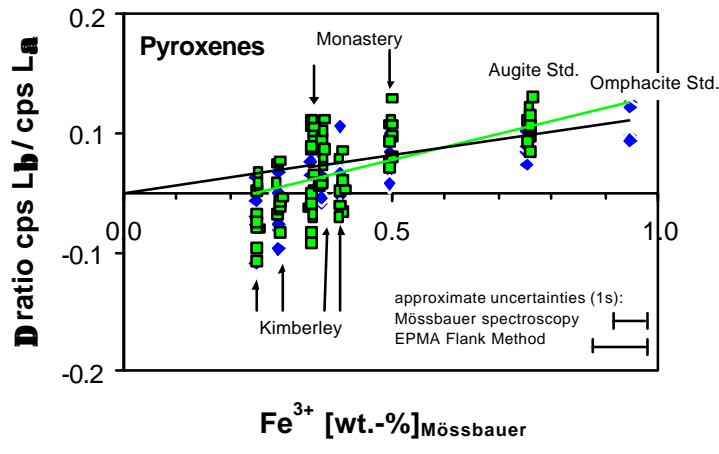

Figure 6: Pyroxene data from Fig. 4 at higher magnification. Two data sets obtained in a time interval of 5 months demonstrate the good reproducibility of the flank method. See text.

In addition to these measurements, garnets from two polished sections of lherzolites from Koffiefontein (total Fe 4.95 wt.-\%) were analyzed. The flank method yields an $\mathrm{Fe}^{3+}$ concentration of 0.08 wt.-\% which is practically zero within the error of the method. This would suggest these samples equilibrated at a lower oxygen fugacity than most known occurrences from the Kapvaal craton ( Woodland and Koch, subm.).

In summary, we have shown that the ferric iron determination by electron microprobe is possible not only for garnets, but also for pyroxenes with the low iron concentrations of mantle minerals. The high precision of the flank method reveals inhomogeneities in standard samples. To further increase the accuracy, the search for suitable standard material will be an important aim for future work.

\section{REFERENCES}

Armstrong, J.T., 1999. Determination of chemical valence state by X-ray emission analysis using electron beam instruments: Pitfalls and promises. Anal. Chem. 71, 2714-2724.

Enders, M., Speer, D., Maresch, W.V., McCammon, C.A., 2000. Ferric/ferrous iron ratios in sodic amphiboles: Mössbauer analysis, stoichiometry-based model calculations and the high-resolution microanalytical flank method. Contrib. Mineral. Petrol. 140, 135-147.

Fialin, M., Wagner, C., Métrich, N., Humler, E., Galoisy, L., Bézos, A., 2001. $\mathrm{Fe}^{3+} / \Sigma \mathrm{Fe}$ vs. FeL $\alpha$ peak energy for minerals and glasses: Recent advances with the electron microprobe. Am. Mineral. 86, 456-465.

Höfer, H.E., Brey, G.P., Schulz-Dobrick, B., Oberhänsli, R., 1994. The determination of the oxidation state of iron by the electron microprobe. Eur. J. Mineral. 6, 407418.

Höfer, H.E., Weinbruch, S., McCammon, C.A.,. Brey, G.P, 2000. Comparison of two electron probe microanalysis techniques to determine ferric iron in synthetic wüstite samples. Eur. J. Mineral. 12, 63-71.

Höfer, H.E. 2002. Quantification of $\mathrm{Fe}^{2+} / \mathrm{Fe}^{3+}$ by electron microprobe analysis - new developments. Hyper. Inter. Special Issue, $5^{\text {th }}$ Seeheim Workshop on Mössbauer Spectroscopy, in press.

Höfer, H.E., Brey, G.P., in preparation. The iron oxidation state in synthetic garnets by electron microprobe: quantification, self-absorption, and implication for other compounds.

McCammon, C.A., 1994. A Mössbauer millipıbe: Practical considerations. Hyper. Inter. 92, 1235-1239.

Paviæeviæ, M.K., Amthauer, G., El Goresy, A. 1989. X -ray emission spectra of iron in silicate garnets. J.- Serb. Chem. Soc. 54, 359-371.

Raeburn, S.P., Ilton, E.S., Veblen, D.R., 1997. Quantitative determination of the oxidation state of iron in biotite using X-ray photoelectron spectroscopy: I. Calibration. II. In situ analyses. Geochim. Cosmochim. Acta 61, 4519- 4537.

Rankenburg, K., 2002. Megacrysts in volcanic rocks of the Cameroon Volcanic Line - constraints on magma genesis and contamination. Ph.D. Thesis, Johann Wolfgang Goethe-Universität, Frankfurt, Germany.

Van Aken, P.A., Liebscher, B. 2002. Quantification of ferrous/ferric ratios in minerals: new evaluation schemes of $\mathrm{Fe} L_{23}$ electron energy-loss nearedge spectra. Phys. Chem. Minerals 29, 188-200.

W ilke, M.,. Farges, F., Petit, P.-E., Brown Jr. ,G.E., Martin, F., 2001. Oxidation state and coordination of $\mathrm{Fe}$ in minerals: An Fe $K$ - XANES spectroscopy study. Am. Mineral. 86, 714-730.

Woodland, A.B. and Peltonen, P. 1998. Ferric iron contents of garnet and clinopyroxene and estimated fugacities of peridotite xenoliths from the Eastern Finland Kimberlite Province. Proc. th $^{\text {th }}$ Int. Kimb. Conf., Cape Town, South Africa, pp. 904-911.

Woodland, A.B. and Koch, M., subm. Variation in oxygen fugacity with depth beneath the Kapvaal craton. Earth Planet. Sci. Letters.

Contact: HE Höfer, Institut für Mineralogie, Universität Frankfurt, Senckenberganlage 28, 60054 Frankfurt, Germany, E-mail: hoefer@em.uni-frankfurt.de 